\title{
WHY DO I SPEND 40 HOURS A WEEK IN AN OFFICE? WHY MEANINGFUL WORK MATTERS AND HOW TO CREATE IT
}

BLAIR MIDDLEBROOK

May 8, 2017 


\section{INTRODUCTION}

Achieving a sense of meaning-i.e., meaningfulness-in one's life is a fundamental human craving; people long for purpose, belonging, and gratitude in their experiences (Frankl, 1985). Meaningfulness's importance and timelessness is emphasized through its exploration by many influential Western thinkers over time, including Socrates, Epicurus, Cicero, Nietzsche, Emerson and Sartre, as well as through many important works of literature such as Hemingway's A Farewell to Arms, Camus's The Outsider, and Hesse's Steppenwolf (Martela, 2010). Although the human need for meaning can spill into all walks of life, one especially salient domain is one's work. Indeed, employees on average spend a total of 90,000 hours working over their lifetimes (Pryce-Jones, 2011). Meaningful work occurs when employees' personal ideals and goals are in alignment with their work role and, more generally, when they view their role as purposeful and significant (Pratt \& Ashforth, 2003; Rosso, Dekas, \& Wrzesniewski, 2010).

Speaking to this importance, scholars argue that meaningful work is one of the most desired characteristics of a job for individuals of all ages (Scroggins, 2008). In fact, many individuals hold meaningfulness in work as a more important outcome than many other external rewards of a job, placing a desire for fulfillment of core personal values, meaning and purpose, self expression, and opportunities to help others as highly desired job characteristics (Caudron, 1997; Martela, 2010). Classic views of employment suggest that workers should adapt to meet the need of an organization, but more modern perspectives convey that organizations should instead adapt to fit their workers, especially as individuals become more inclined to question the nature and meaning of work (Cartwright \& Holmes, 2006).

This view has seen only modest application in practice, however, some estimates suggest that as much as $87 \%$ of employees worldwide are disengaged in their work, in significant part due to lack of perceived meaningfulness (Keane, 2015). Helping employees create and find meaningfulness in their work can have serious implications for an organization's human capital (Herman \& Gioia, 1998). Indeed, when employees find their work meaningful, they are more than three times as likely to stay in their jobs, are more creative in their work, and generally demonstrate more organizational commitment (Amortegui, 2014; Cohen-Meitar, Carmeli \& Waldman, 2009; Steger, Dik \& Duffy, 2012). Overall, organizations should have strong motives beyond just altruism to develop a workforce of employees who experience their work as meaningful.

The study of meaningfulness at work is rooted in identity theory, whereby meaningfulness emerges from a congruence between the values and personal mission of an individual and the work s/he is doing. The connection to identity theory sets the foundation for significant research into the antecedents and results of meaningful work. A variety of practices ranging from individual efforts to organization-wide programs can contribute to increasing an employee's sense of meaningfulness in his or her work. These practices are relevant to an organization as it is able to reap the benefits of employees who feel their work is meaningful at a larger scale if they intentionally craft a workplace that promotes a sense of meaningfulness.

Despite the amount of research that has been done on the outcomes of meaningful work and on what contributes to fostering a sense of meaningfulness, there is a lack of literature connecting and integrating these concepts. Addressing these concerns, this work aims to synthesize the research regarding practices that can increase employees' senses of meaningfulness in their work and the results of an increased sense of meaningfulness for individual employees and organizations as a whole, with the ultimate goal of creating a taxonomy that encompasses the broad practice types. Moreover, I provide empirical data linking each of the broad practices types with employees' perceived levels of meaningfulness and other important work outcomes. Finally, I provide a preliminary analysis regarding which sources (e.g., supervisors, coworkers, formal organizational practices) the various practices are most influenced by. By linking and integrating these concepts, practitioners will be able to more effectively understand how meaningfulness is developed and what practices can be practically implemented to foster an environment of meaningfulness in an organization.

\section{THEORETICAL FRAMEWORK}

People actively seek meaning in all aspects of their lives, including in their work roles (Cohen-Meitar et al., 2009). Meaning creation is a process that individuals use in an effort to make sense of significant questions such as "Who am I?" and "Where do I belong?" and other similar existential thoughts (Cohen-Meitar et al., 2009). This process of meaning creation has created two distinct perspectives of one's work: work meaning and meaningful work. The study of meaningfulness is associated with, but not the same as, meaning in work. In the section below, I distinguish between the two concepts. 


\section{Meaning vs. Meaningfulness}

Scholars generally define meaning in work as employees' understandings of what they do at work as well as the significance of what they do (Rosso et al., 2010). Earlier studies of work meaning focus on the context for and motivations of sense-making in work. In an organizational setting, work meaning has focused on making sense of problematic experiences of work and redefining and altering the meaning of those problematic experiences (Wieck, 1995). However, there is a distinction between meaning in work and meaningfulness in work (Monnot \& Beeher, 2014).

Meaning is a result of making sense of something, which in work occurs when an individual employee interprets what one's work or organizational life connotes (Gray, Bougon, \& Donnellon, 1985). Perceptions of meaning are determined by an individual, with influence from social contexts and are the output of having made sense of something, in this case, work (Rosso et al., 2010). Meaningfulness, on the other hand, refers to the magnitude or amount of significance one feels in work (Pratt \& Ashforth, 2003). It is thus possible for individuals to assign the same meaning to work but experience different degrees of meaningfulness in that work (Monnot \& Beeher, 2014). Meaningful work has become a more relevant concept in recent years because it is more closely tied to an effect on work outcomes due to its connection to identity. Defining the meaning of work does not necessarily constitute a closer connection or passion for the work, whereas fostering a sense of meaningfulness in work does. For this reason, this work will focus on meaningfulness, in order to tie the effect of this sense to specific, positive outcomes.

\section{Defining Meaningfulness}

Because there are no universally accepted definitions of what constitutes a meaningful life, it is difficult to precisely assert what comprises meaningful work (Michaelson, Pratt, Grant \& Dunn, 2014). As a result, various literature presents different definitions of meaningfulness in work. Bowie (1998) defines meaningful work as work that is freely entered into, allows the worker to exercise his autonomy and independence, enables the worker to develop her rational capacities, provides a wage sufficient for physical welfare, supports the moral development of employees, and is not paternalistic. Yeoman (2014) defines it as a value that is broader and richer than happiness or morality that comes from engaging in work worthy of loving. Kahn (1990) defines meaningful work as "a sense of return on investments of self in role performance" (Kahn, 1990; p. 705) and Chalofsky defines it as work that "gives essence to what we do and brings a sense of fulfillment to our lives" (Chalofsky, 2010, p. 19). Other scholars provide facets to the definition of meaningfulness that require categorization of sources of meaningfulness. Cohen-Meitar et al. (2009) describe two forms of meaningfulness: meaningfulness at work (perceived organizational identity and external prestige) and in work (challenge and freedom in what the person is doing). Rosso et al. (2010) state that meaningfulness can be defined individually or as a result of culturally or socially enforced worldviews or value systems, and each of these contributing factors play into shaping an employee's sense of meaningfulness in work. Pratt and Ashforth (2003) also explain that meaningfulness is a subset of sensemaking, where the sense making attempts to answer broad, existential questions such as "Why am I here?"

The definition that is most relevant to the research conducted here is Pratt and Ashforth's (2003) definition: meaningful work is work that is perceived as purposeful and significant. This definition is useful due to its broad and encompassing nature, as well as its emphasis on perception, highlighting the importance of individual' unique construction and experience in crafting a sense of meaningfulness in work.

\section{Meaningfulness through Identity Theories}

Meaningfulness has often been studied through the lens of identity theories, focused on the way in which we link who we are with what we do. In this regard, the "path" to meaningfulness is through identity, and is often associated with fit, match and alignment between identity and work (Pratt \& Ashforth, 2003). Work is said to be experienced as meaningful when it confirms or promotes an individual's perception of his or her ideal self and is consistent with who he or she perceive him or herself to be, thus promoting a close tie between identity and sense of meaningfulness (Scroggins, 2008). Supporting this view, Treadgold (1999) found that there exists a positive correlation between an individual's sense of meaningfulness in his or her work and his or her clarity of self-concept.

Identity theories assert that work helps create, express, and confirm one's self conceptions and that who one is, or how one identifies himself, coalesces around the roles one plays in life (Pratt \& Ashforth, 2003; Stryker \& 
Serpe, 1982). Cooley (1902) discussed the idea of one's "looking glass self" and how the way in which others view someone affects how that person views himself. Similarly, social identity theory describes how group categories and memberships contribute to the definition of one's identity (Ashforth \& Mael, 1989). Freud asserted that when individuals are able to engage in meaningful work that gratifies instinctual drives, that work allows for healthy ego development and deters neurosis (Treadgold, 1999). These theories, taken together, contribute to the link between meaningfulness and the people one surrounds him/herself with. In an organizational setting, this entails alignment with the goals, values, and beliefs of an organization (Pratt \& Ashforth, 2003).

\section{Measuring Meaningfulness}

Due to the variety of ways to define meaningfulness, as well as its intangible nature, measuring the presence of meaningfulness in an organizational setting is challenging. Nevertheless, there are several notable approaches. Pratt and Ashforth (2003) presented a very broad approach to measuring meaningfulness by proposing that meaningfulness is measured through evaluating the extent to which organizational practices enhance the roles, tasks, or work that individuals perform or enhance the characteristics of group membership and its goals, values, and beliefs. Hackman and Oldham (1976) developed a more quantitative measure through the Job Diagnostics Survey, which uses two pairs of items to evaluate sense of meaningfulness with regard to their personal feelings and perceptions of coworkers' feelings of whether job tasks seem useless or trivial and whether the work is meaningful (Steger et al., 2012). Others have taken the Job Diagnostics Survey (Hackman and Oldham, 1976) and adapted it to more specific use, such as Steger et al. (2012), who created a scale of measurement of meaningfulness which measures psychological meaningfulness, making meaning through work, and greater good motivations through a 40 question inventory based on principles of the Job Diagnostics Survey, called the Work and Meaning Inventory.

\section{Sources of Meaningfulness}

The concept of meaningful work has been studied with many approaches, which have produced a multitude of understandings of the sources of meaningfulness and the categories of areas that a sense of meaningfulness can be developed. As a result, there are a variety of sources that contribute to an employee's sense of meaningfulness. A meaningful life was described very early on as doing something one believes in, living virtuously, and attaining valuable goals by Aristotle's concept of eudemonia (Cartwright \& Holmes, 2006). More recently, research has developed similar categories for the sources of meaningfulness in work. Martela (2010) illustrated meaningfulness as deriving from an active, ongoing relationship between an individual, the job's characteristics, the organization, and society. Rosso et al. (2010) categorized this principle with four major sources of meaningfulness in work: the self, other persons, the work context, and spiritual life. These four categories illustrate the internal and external factors that can contribute to a sense of meaningfulness and demonstrate the complexity involved in developing a strong sense of meaningfulness in work. I will elaborate on each of these four categories by providing supporting research into the ways each of these sources contributes to meaningfulness, as well as providing examples as to how this can be practiced in an organizational setting.

The Self. Pratt and Ashforth (2003) assert that individuals are not just passive recipients of meaningfulness, but rather are active participants in creating the meanings that express and confirm their desired sense of self. Thus many factors contribute to fostering a sense of meaningfulness that derive from actions or perspectives of an individual. Employees take cues from others that help them discern the meaning of their job and seek out social situations at work where their view of the meaning of their job, role, and self is enforced, aligning internal and external sources of meaningfulness (Wrzesniewski et al., 2003). Similarly, Pratt and Ashforth (2003) explain that meaningfulness arises through an integration of identity with roles in work groups and Shamir (1991) explained that meaningfulness comes from the interaction between work tasks, the context of the work, and an individual's self concept, emphasizing an individual's process of identity integration as an important source of meaningfulness. Additionally, Yeoman (2014) explains that the experience of meaningfulness is more likely to occur when a person becomes actively connected to a worthy object, or something or someone of value, such that they are gripped, excited, and involved by it, emphasizing the need for personal connection to one's work to experience meaningfulness. 
Martela (2010) also argued that meaningful work is essentially a match between an individual's need for meaning and the meaning a job is able to offer, which can be understood through three key questions: 1) Where do I belong? 2) How do I connect and relate to others? 3) What is my value contribution to others? (Cartwright \& Holmes, 2006). Each of these questions focus on an individual connection to work being done and require personal engagement in reflection and thought. Individual perspectives on work role identity, work values, and intrinsic work orientation also play essential roles in developing a sense of meaningfulness and are established by an individual (Steger et al., 2012). Pratt, Pradies, and Lepisto (2013) categorized the ways that meaningfulness can be experienced by an individual into a craftsman orientation, serving orientation, and kinship orientation. A craftsman organization entails finding work meaningful through fulfillment in the work itself and doing a job well; a serving orientation entails finding a job meaningful through the joy of helping others through work; and a kinship orientation entails fulfillment through family-like connections with coworkers (Pratt et al., 2013). These unique ways an individual can experience meaningfulness demonstrate the importance of "the self" in deriving and fostering meaningfulness.

The principle can be put into practice in numerous ways, a few of which I will discuss here. First, an individual's perspective on his or her work and how it connects to his or her identity is critically important in contributing to the degree to which s/he understand his or her work to be meaningful (Wrzesniewski et al., 2003). For example, hospital cleaning staff members could view their work as simply a source of income, or they may see themselves as an integral part of a wider organization that is saving lives and promoting better health, each producing a widely different sense of meaningfulness (Wrzesniewski et al., 2003). Another individual practice involves integrating personal identity with role and membership in the organization, which is essential to capitalizing on the significant influence of identity theories in creating meaningfulness, as discussed earlier (Cohen-Meitar et al., 2009). So, an individual must develop his own sense of understanding of an organization's identity and make sense of that into his own self-concept in order to experience a sense of meaningfulness in his work (Cohen-Meitar et al., 2009). Additionally, employees can engage in rewarding interpersonal encounters at work that allow them to feel that they are contributing value to the lives of others around them and that their time is being used in a significant way (Martela, 2010).

Other Persons. Other persons play an important role in establishing an individual's sense of meaningfulness in ways including as coworkers, as members of society, as managers, and as beneficiaries of an individual's work (Martela, 2010). Others outside of an organization make up society as a whole, and thus society plays a major role in shaping an individual's sense of meaningfulness. Coworkers contribute to the social construction of meaningfulness among individuals within work groups or departments (Pratt and Ashforth, 2003). Additionally, coworkers and managers are responsible for providing feedback to individuals, which is an important source of developing a sense of meaningfulness (Hackman and Oldham, 1976, 1980). Providing positive feedback is especially important, as receiving positive feedback allows individuals to recognize the ways in which their work is fulfilling their need for meaningfulness in life (Martela, 2010). Positive feedback can be delivered through expressions of gratitude, pointing out how an individual's work has efficacy, expressing appreciation and respect, and engaging in rewarding interactions, all of which boost an employee's sense of meaningfulness (Martela, 2010).

Coworkers also provide individuals an opportunity to engage in rewarding interactions, which boosts an individual's sense of meaningfulness (Kahn, 1990). Relatedly, coworkers are also the reason a kinship orientation toward experiencing meaningfulness can exist in Pratt et al.'s (2013) model. This orientation asserts that individuals can understand their work as meaningful if they experience a close connection with the people they work with, again demonstrating the role of coworkers as others in establishing meaningfulness (Pratt et al., 2013).

Team leaders, or managers, in particular have many opportunities to influence an individual's sense of meaningfulness. For example, managers can foster meaningfulness in a team by articulating an inspiring vision and linking it to shared values (Michaelson et al., 2014). Leaders can also promote meaningfulness by creating clear goals for their subordinates and opportunities to see how the completion of these goals impacts the organization (Herman \& Gioia, 1998).

Beneficiaries of an individual's work are another important group of "other persons." In Cartwright and Holmes's (2006) three questions for comprehending meaningfulness, the question of "What is my value contribution to others?" demonstrates the importance of understanding the impact of one's work in experiencing it 
as meaningful. The serving orientation of Pratt et al.'s (2013) model also demonstrates the importance of this principle, as it describes how individuals can find their work meaningful in feeling like they are serving others and feel like they are making an impact on people outside themselves with their work. For example, a study found that radiologists who saw a photo of the person whose x-rays they were reading wrote longer reports and had an increase in diagnostic findings for those patients, along with an increased sense of meaningfulness in their work (Michaelson et al., 2014).

The Work Context. Not surprisingly, the context of an individual's work is an important component in fostering a sense of meaningfulness in work (Rosso et al., 2010). Meaningfulness is derived from the interplay between the job, role, and self, two thirds of this equation being related to work context (Wrzesniewski et al., 2003). Shamir (1991) echoed this structure by proposing that meaningfulness comes as a result of the interaction between work tasks and self-concept. Organizations can design jobs that provide meaning to satisfy the need for meaning desired by individuals, the satisfaction of which brings meaningfulness (Martela, 2010). Organizations also can design jobs that allow employees to experience meaningfulness through at least one of the three orientations (kinship, craftsman, serving) described by Pratt et al. (2013). Kahn (1990) also explains that meaningfulness can come from challenge, variety, and opportunities for creativity in work, all of which are included in the work context. Chalofsky (2010) echoes this framework by asserting that a meaningful workplace includes elements of a values-based culture, how organizations care about employees, the organizational mission, and employee socialization within organizations.

With this understanding of the characteristics that, when present in the work context, can increase an individual's sense of meaningfulness, there are a few practices that organizations can implement to capitalize on this source. Organizations can structure jobs to include aforementioned characteristics such as opportunity for creativity, as well as characteristics that are a part of Hackman and Oldham's $(1978,1980)$ job characteristics model. These factors are task identity (completing a task from start to finish), task significance (the work has some positive impact), skill variety, autonomy and feedback, and are powerful antecedents to experiencing meaningfulness in work (Hackman and Oldham, 1978, 1980).

Organizations can also strive to create a culture of community, encouraging support and collaboration between employees in order to capitalize on the role of connectedness to fellow employees in boosting experienced meaningfulness (Boverie \& Kroth, 2001; Herman \& Gioia, 1998). By creating sharing information with employees more openly, an organization can develop a work context of trust, which will also increase an individual's sense of meaningfulness (Gioia \& Chittipeddi, 1991). An example of an effective way to create this culture is Open Book Management, a practice designed by Jack Stack of the Springfield Remanufacturing Company (Bowie, 1998). This strategy involves providing every employee with complete information, expecting them to know the financial details of the organization, and giving them power to make changes to the bottom line, as they know how their work contributes to the company overall (Bowie, 1998).

Organizations can also improve meaningfulness in the work context by considering the greater needs of their employees through training and education, as well as opportunities for pursuits outside of the formal job role. Organizations that provide training, opportunities for learning, increased responsibility, cross team collaboration, and occasions for implementing solutions see an increased sense of meaningfulness among their employees, as they feel their time is being used effectively for the future and that their strengths are being developed (Herman \& Gioia, 1998; Bowie, 1998). Organizations that offer enhancements to life outside of a job such as flex time, career break schemes, or the opportunity to volunteer or contribute part of their pay check to charity also see employees experiencing a higher degree of meaningfulness in their work (Bowie, 1998; Cartwright \& Holmes, 2006).

Spiritual Life. Though there is far less literature on the connection between spiritual life and meaningfulness in work, especially in the organizational and applied psychology literatures, spirituality is nonetheless a noteworthy source of meaningfulness (Steger et al., 2012). Spirituality in work is defined by Cartwright and Holmes (2006) as the harmonization of an individual's job and his or her personal values and desire to make a difference in the world. Dik, Duffy, Allan, O'Donnell, Shim, and Steger (2015), among others, found that supporting the integration of work and spirituality lead to a higher degree of meaningfulness for employees. 


\section{Outcomes of Meaningfulness}

Organizations that are able to effectively foster a sense of meaningfulness in the work of their employees impact employees individually and benefit the organization as a whole in a number of ways. Below I discuss the most significant outcomes for the outcomes of this study.

Individual Outcomes. Dik et al. (2015) propose that a sense of meaningfulness contributes to individual happiness and advances individual well-being. Similarly, Cohen-Meitar et al. (2009) argue this by explaining that a sense of meaningfulness is critical for enabling an individual's identification processes and positive psychological experiences, which improves creativity. When an individual experiences job fit and meaningfulness, s/he is more likely to be engaged in his or her work and to perform with energy and enthusiasm (Shuck, Reio \& Rocco, 2011). Additionally, employees who feel their work is meaningful view their work as more central and important (Harpaz \& Fu, 2002), place higher value on work (Nord, Brief, Atieh, \& Doherty, 1990), and report greater job satisfaction (Kamdron, 2005). People who feel their work serves a higher purpose also report greater job satisfaction and work unit cohesion (Sparks \& Schenk, 2001).

More specific relationships identified in the literature suggest that meaningful work is positively linked to organizational citizenship behaviors, career commitment, job satisfaction, intrinsic work motivations, problem-focused coping, work unit cohesion, work effort, and clarity of self-concept (Steger et al., 2012; Treadgold, 1999; Martela, 2010). Conversely, meaningfulness has been found to be negatively correlated with hostility, depression, emotion-focused coping, depression, anxiety, and substance abuse (Steger et al., 2012; Treadgold, 1999; Martela, 2010). Lack of meaningfulness is also associated with worker alienation, loneliness, ostracism, rejection, and eventually burnout for their employees (Michaelson et al., 2014; Shuck et al., 2011). Not surprisingly, employees who find their work meaningful have perceptions of greater meaning in life as a whole (Dik, Sargent, \& Steger, 2008).

Organizational Outcomes. Organizations as a whole can also see significant benefits from an increased sense of meaningfulness among their employees. In fact, meaningful experience at work is an important feature among the most successful and innovative companies (Bains, 2011). A study by Towers Perrin stated that building employee engagement through experienced meaningfulness is one of the most critical tasks facing organizations today (Scroggins, 2008). A sense of meaningfulness is a cornerstone to developing work related attitudes that influence commitment, performance and intention to stay at an organization (Shuck et al., 2011). As alluded to previously, employees who feel their work is meaningful exhibit more organizational commitment and many other underlying work motivations, making them more valuable employees in general, and also report fewer days absent from work and are less likely to have withdrawal intentions (Steger et al., 2012; Scroggins, 2008).

Relatedly, meaningful work is more likely to be perceived as a calling, which leads employees to spend more discretionary, unpaid hours working (Wrzesniewski, McCauley, Rozin, \& Schwartz, 1997), to have more faith in management, and to have better work-team functioning (Wrzesniewski et al., 2003). Fostering a culture of meaningfulness also benefits an organization as it prompts employees to work well together, create supportive relationships, freely share information, and energize one another to create further work engagement (Cross, Baker \& Parker, 2003). Further, teams where team members experience higher senses of meaningfulness are found to have less conflict, more commitment to the team, and healthier group processes (Wrzesniewski et al., 2003). Additionally, organizations are able to benefit from all the individual effects that employees experience personally, as these create a healthier, engaged, satisfied, and committed work force for the organization. Finally, organizations that are perceived as meaningful workplaces have a major advantage in recruiting and selecting employees, as well as retaining their employees (Martela, 2010).

tants (Edris, 2007; Xu et al., 2008). The risk of thymol is the potential to cause skin irritation common among essential oils, but this irritation is dose dependent (Bondi, 2010). Through a research and mitigation process, a formulation of thymol $0.05 \%$ was shown to be non-toxic to land and aquatic life, and it met the microbiological requirements for EPA registration as a disinfectant. In addition, when exposing 54 human participants to thymol $0.05 \%$, only one participant was shown to have skin irritation resulting from application (Bondi, 2010). As this ar- 


\section{RESEARCH QUESTIONS}

The promotion of meaningfulness in the organizational context can be pursued through a variety of practices, some of which were mentioned in the sources of meaningfulness section. However, a system of organization or categorization of these practices does not currently exist, but the development of such a system would provide better understanding of the strategies and themes that influence these practices. A system of categorization for practices that promote meaningfulness would also provide insight into which of these themes are most influential in an individual's sense of meaningfulness in his or her work. Additionally, the reviewed literature involves an assessment of the different sources that contribute to creating a sense of meaningfulness, but does not evaluate the extent to which each of these sources influences meaningfulness in comparison to each other, or in terms of certain categories of practices. Though meaningfulness has been linked to many organizational outcomes, there lacks a comprehensive investigation into these outcomes concurrently and in a quantitative way. Addressing these omissions in the literature, I advance the following:

Research Question 1: What are the different types of practices that promote meaningfulness in an organization?

Research Question 2: How influential is each category of practices that promote meaningfulness? Research Question 3: (a)Which sources of meaningfulness are most influential in promoting meaningfulness within each category? And (b) Which organizational outcomes are most closely connected to meaningfulness?

\section{STUDY ONE}

In the next section, I construct a taxonomy of the types of practices that promote meaningfulness in an organizational setting. This taxonomy was generated as a result the comprehensive research I conducted on the many factors that have been linked to an increased sense of meaningfulness for employees. The taxonomy I created was validated through a quantitative validation study with subject matter experts. This study provides results for research question 1, while providing the framework to answer research questions 2 and 3.

\section{STUDY 1 METHODS}

In order to evaluate the different types of practices that promote meaningfulness in an organization, I conducted an extensive literature review across many facets of the shaping of an individual's sense of meaningfulness in his or her work. Using sources including Google Scholar, JSTOR, Business Source Complete, and Wiley Online Library, I reviewed literature from a wide variety of academic journals and books, as well as more mainstream media such as the Harvard Business Review. Accessing literature through this broad range of sources provided diversity of perspective and focus of study. This literature review comprehensively coalesced a widely disjointed set of literature to provide an extensive compilation of the major, most influential practices that can be implemented by organizations, supervisors, or individuals in an organization to increase meaningfulness for employees. The list of practices can be seen in table 1. In conducting this review, I became acquainted with many existing frameworks for understanding themes that exist among these practices, but no source provided clear categorization for understanding and organizing these practices.

Using the thematic frameworks present in the various literature I reviewed, as well as perspectives I developed in examining this topic extensively, I began looking for commonalities among these practices. After identifying these commonalities, I began using an iterative process of creating, separating, combining, and adjusting categories that could reasonably contain the identified practices. After careful evaluation and modification, I designated six major categories in which each of the practices could be placed. These categories were:

(1)building/increasing trust in the workplace,

(2)connecting identity and work,

(3)fostering connection and community among employees,

(4)allowing employee growth through training and development,

(5)enhancing/considering life outside of work, and

(6)job design/promoting job 


\section{Comprehensive List that Promote Meaningfulness}

- Leaders articulating an inspiring vision and linking it to shared values and goals

- Leaders exercising a method of transformational leadership

- Allowing greater transparency in the way information is shared within a team

- Leaders allowing team members the authority to made decisions independently

- Leaders creating clear goals and showing how completion of goals impacts the organization

- Leaders crafting a work role or assigning projects to employees that will create a fit between a worker's self concept and their tasks

- Leaders fostering a culture of meaningfulness among all members of a team

- Leaders providing feedback often, directly and in a timely matter

- Individuals developing their own sense of understanding of an organization's identity and making sense of that into personal self-concept

- Individuals giving positive cues to contribute to creating more meaningful work environments

- Individuals engaging in rewarding interpersonal encounters at work that feel as though they contribute value to the lives of others

- Organizations structuring jobs to emphasize sill variety, task identity, task significance, autonomy, and feedback

- $\quad$ Organizations enabling employees to have challenge and freedom in their work

- Providing clear and attainable goals in a job or task

- Creating strong community in a workplace, providing a nurturing environment and fostering a sense of community

- Crafting an organizational setting that is sensitive to employee's concerns outside of the workplace (such as offering flex time)

- Offering secondments and career break schemes

- Encouraging and offering opportunities for employees to be involved in community service or donating a percentage of their income to charity

- $\quad$ Providing employees access to more information to create trust and ability to see how their work personally fits into an organization's overall work

- Providing ongoing coaching and opportunities for feedback and encouragement toward growth

- $\quad$ Creating opportunities for employees to learn-academically, related to the job, and personally

- Offering employees opportunities for cross training or cross utilization in company projects

- Recruiting and selecting employees whose personal values connect to those of the company

- Implementing focus on quality

- Connecting employees to the beneficiaries of their work

- $\quad$ Supporting the integrating of spirituality and work

- Promoting a sense of gratitude for life

Table 1

\section{Proposed Taxonomy}

Building/increasing trust in the workplace: this category includes activities that lead to an increased level of trust between coworkers, between supervisors and their subordinates, or other employee-to-employee relationships. These practices also include activities that make employees feel that the organization as a whole trusts their employees individually and as a whole.

Job design/promoting Job Characteristics Model: this category includes practices that can be intentionally fostered in crafting a role withing an organization. Specifically, this includes any practices that will allow employees to experience aspects of the Job Characteristics Model including skill variety, task identity, and task significance.

Connecting identity and work: Experiencing meaningfulness is closely linked to an individual's identity (including concepts like self concept, value, etc.) to connect with his or her work in some regard.

Fostering connection and community among employees: this category includes activities that encourage or allow employees to develop friendships with each other, feel connected to each other, and experience camaraderie in the in the workplace.

Enhancing/considering life outside of work: this category includes practices that can be implemented to allow employees to maintain balance between their life as employees at the organization and other areas of their lives outside of that such as hobbies, family, or community interests. These practices allow employees to feel that organizations support their personal endeavors and are willing to accommodate to the needs of their lives outside of work.

Allowing employee growth throughout training and development: this category includes activities that allow employees to feel like their time working in a role is preparing them for the future, likely a higher position. This includes activities such as learning through unique hands-on experience or training in a "classroom" setting supported by the organization. 
Descriptions of these categories can be seen in table 2. In order to validate the results of this process, I created a quantitative content validation survey and elicited input from subject matter experts in the field. saying "family member pushback might be an issue. Whenever I buy something different... like organic mustard, the family was just like, 'No, it doesn't taste as good!'”

The content validation survey consisted of the complete list of practices I had compiled through conducting a review of existing literature and an option for each of the six categories I had created to designate if the practice did not fit at all (value $=0$ ), had some fit (value=1), or was a definite fit (value=2). Ten subject matter experts provided their input and the results of their evaluations were quantified and compiled. These experts consisted of individuals holding a PhD in Management or Industrial Organizational Psychology working at Universities across the United States. In creating the categories, I predicted which category I thought each practice would best fit into, and did not share this prediction with the respondents. For each answer, evaluated the mean of the responses of the ten subject matter experts to determine the placement of each practice into the six categories.

\section{STUDY ONE RESULTS}

I organized the results of the subject matter experts by taking the average of their responses based on the assigned quantitative values. To determine the subject matter experts' collective selection of a category for a given practice, I identified the highest mean of the six categories. The results can be seen in table 3 below. The grey shaded boxes represent the category selected by the subject matter experts, by taking the category that had the highest mean score of the 10 subject matter experts, and the asterisk designates the category I predicted the practice would fall into.

Of the twenty-nine practices evaluated, twenty-five practices scored a mean of above 1.5 (out of two), designating that these categories provided a strong fit for the practices to be categorized by. Additionally, only one practice differed on classification between what I had predicted and what subject matter experts designated. Even though my prediction differed, this practice received a mean score of 1.6 in the category I had predicted it would fit best into, designating that does possess strong identity with that category. Only one practice, "implementing a focus on quality" scored very low for any category, designating that it could not be effectively placed in any of these six categories. With the exception of that practice, all others on the list fit well into one of the six categories, validating the effectiveness of a taxonomy for this designated list of practices (with the exception of the one practice). These results can be seen in table 3 .

\section{STUDY ONE DISCUSSION}

The results from Study 1 indicated that the most prevalent practices for increasing employee meaningfulness can be reasonably categorized into the six overarching categories I identified. This contribution incrementally advances the existing literature on practices that induce meaningfulness into a coherent and logical framework.. In Study 2 I extend this contribution to examine the relative impacts of each particular practice type with employee perceptions of meaningfulness (Research Question 2) and other potential work outcomes (e.g., organizational commitment, creative performance, and organizational citizenship behaviors); I also explore the most common sources (e.g., the self, supervisors/managers, and others outside of work) from which meaningfulness-inducing practices emerge (Research Question 3a, b). 


\begin{tabular}{|c|c|c|c|c|c|c|}
\hline & $\begin{array}{l}\text { Building } \\
\text { Trust }\end{array}$ & $\begin{array}{l}\text { Job } \\
\text { Design }\end{array}$ & $\begin{array}{l}\text { Connecting } \\
\text { Identity }\end{array}$ & $\begin{array}{l}\text { Non-Work } \\
\text { Life }\end{array}$ & $\begin{array}{l}\text { Creating } \\
\text { Community }\end{array}$ & Growth \\
\hline $\begin{array}{l}\text { Leaders articulating an inspiring vision and linking it to } \\
\text { shared values and goals }\end{array}$ & 0.90 & 0.60 & $1.7^{*}$ & 0.10 & 0.80 & 0.3 \\
\hline $\begin{array}{l}\text { Leaders exercising a method of } \\
\text { transformational leadership }\end{array}$ & $1.44^{*}$ & .60 & 1.10 & 0.20 & 0.44 & 0.5 \\
\hline $\begin{array}{l}\text { Leaders showing personal commitment to the role and } \\
\text { creating trust in the team by acting with integrity }\end{array}$ & $2^{*}$ & 0.00 & 0.60 & 0.10 & 0.80 & 0.30 \\
\hline $\begin{array}{l}\text { Allowing greater transparency in the way information is } \\
\text { shared within a team }\end{array}$ & $2^{*}$ & 0.60 & 0.40 & 0.00 & 1.00 & 0.20 \\
\hline $\begin{array}{l}\text { Leaders allowing team members the authority to make } \\
\text { decisions independently }\end{array}$ & 1.50 & $1.9^{*}$ & 1.20 & 0.50 & 0.50 & 1.50 \\
\hline $\begin{array}{l}\text { Leaders creating clear goals and showing how completion } \\
\text { of goals impacts the organization at large }\end{array}$ & 0.70 & $1.6^{*}$ & 1.20 & 0.00 & 0.70 & 0.60 \\
\hline $\begin{array}{l}\text { Leaders crafting a work role or assigning projects to } \\
\text { employees that will created a fit between a worker's self } \\
\text { concept and their tasks }\end{array}$ & 0.70 & 1.30 & $1.8^{*}$ & 0.40 & 0.40 & 1.20 \\
\hline $\begin{array}{l}\text { Leaders fostering a culture of meaningfulness among all } \\
\text { members of a team }\end{array}$ & 1.40 & 0.70 & 1.10 & 0.20 & $1.7^{*}$ & 0.20 \\
\hline $\begin{array}{l}\text { Leaders providing feedback often, directly and in a timely } \\
\text { matter }\end{array}$ & 1.50 & $1.9^{*}$ & 0.40 & 0.00 & 0.10 & 1.50 \\
\hline $\begin{array}{l}\text { Individuals developing their own sense of understanding } \\
\text { of an organization's identity and making sense of that into } \\
\text { personal self-concept }\end{array}$ & 0.30 & 0.60 & $2^{*}$ & 0.40 & 0.10 & 0.10 \\
\hline $\begin{array}{l}\text { Individuals giving positive cues to contribute to creating } \\
\text { more meaningful work environments }\end{array}$ & 0.80 & 0.60 & 0.90 & 0.20 & $0.9^{*}$ & 0.20 \\
\hline $\begin{array}{l}\text { Individuals engaging in rewarding interpersonal encoun- } \\
\text { ters at work that feel as though they contribute value to } \\
\text { the lives of others }\end{array}$ & 0.90 & 0,90 & 1.20 & 0.20 & $2^{*}$ & 0.30 \\
\hline $\begin{array}{l}\text { Organizations structuring jobs to emphasize skill variety, } \\
\text { task identity, task significance, autonomy, and feedback }\end{array}$ & 0.10 & $2^{*}$ & 1.00 & 0.00 & 0.30 & 0.50 \\
\hline $\begin{array}{l}\text { Organizations enabling employees to have challenge and } \\
\text { freedom in their work }\end{array}$ & 1.00 & $1.7^{*}$ & 1.00 & 0.60 & 0.20 & 1.20 \\
\hline Providing clear and attainable goals in a job or task & 0.30 & $1.2^{*}$ & 0.20 & 0.00 & 0.00 & 1.00 \\
\hline $\begin{array}{l}\text { Create strong community in a workplace, providing a nur- } \\
\text { turing environment and fostering a sense of community }\end{array}$ & 1.30 & 0.20 & 1.10 & 0.40 & $2^{*}$ & 0.00 \\
\hline $\begin{array}{l}\text { Crafting an organizational setting that is sensitive to } \\
\text { employees' concerns outside of the workplace (such as } \\
\text { offering flex time) }\end{array}$ & 1.20 & 0.60 & 0.90 & $2^{*}$ & 0.30 & 0.10 \\
\hline Offering secondments and career break schemes & 0.70 & 0.40 & 0.40 & $1.6^{*}$ & .10 & 0.60 \\
\hline $\begin{array}{l}\text { Encouraging and offering opportunities for employees to } \\
\text { be involved in community service or donating a percentage } \\
\text { of their income to charity }\end{array}$ & 0.44 & 0.67 & 1.10 & $1.7^{*}$ & 0.80 & 0.00 \\
\hline $\begin{array}{l}\text { Providing employees access to more information to create } \\
\text { trust and ability to see how their work personally fits into } \\
\text { an organization's overall work }\end{array}$ & $1.9^{*}$ & 1.20 & 1.20 & 0.10 & 0.50 & 0.50 \\
\hline $\begin{array}{l}\text { Providing ongoing coaching and opportunities for feed- } \\
\text { back and encouragement toward growth }\end{array}$ & 1.00 & 1.00 & 0.70 & 0.20 & 0.20 & $1.8^{*}$ \\
\hline $\begin{array}{l}\text { Creating opportunities for employees to learn-academi- } \\
\text { cally, related to the job, and personally }\end{array}$ & 0.60 & 0.60 & 0.90 & 1.00 & 0.20 & $2^{*}$ \\
\hline $\begin{array}{l}\text { Offering employees opportunities for cross training or } \\
\text { cross utilization in company projects }\end{array}$ & 0.50 & 1.60 & 0.60 & 0.20 & 0.60 & $1.88^{*}$ \\
\hline $\begin{array}{l}\text { Recruiting and selecting employees whose personal values } \\
\text { connect to those of the company }\end{array}$ & 0.80 & 0.00 & $1.6^{*}$ & 0.10 & 0.90 & 0.00 \\
\hline Implementing focus on quality & $0.5^{*}$ & $0.5^{*}$ & 0.40 & 0.00 & 0.00 & 0.30 \\
\hline Connecting employees to the beneficiaries of their work & 0.50 & $1.8^{*}$ & 1.40 & 0.30 & 0.70 & 0.30 \\
\hline Supporting the integrating of spirituality and work & 0.80 & 0.10 & $1.6^{*}$ & 1.90 & 0.60 & 0.10 \\
\hline Promoting a sense of gratitude for life & 0.50 & 0.10 & 1.20 & $1.7^{*}$ & 0.60 & 0.10 \\
\hline
\end{tabular}




\section{STUDY TWO}

In order to use the categories presented in Study 1 to examine the most effective strategies for organizations to implement in promoting meaningfulness, I conducted a survey to gain insight to the experience of individuals in various work environments. The resulting data provides insight into the relative strength of the relationship between meaningfulness and each of the practices from Study 1, the relationship between meaningfulness and each of the six categories in the proposed taxonomy, the degree of influence of each of the sources that impact each category, and the relationship between meaningfulness and other organizational outcomes.

\section{STUDY TWO METHODS}

For this study, I aimed to assess each of the six categories extensively, including looking at the role of each category that promotes meaningfulness and understanding the sources that most contribute to implementing each category. Additionally, I wanted to investigate how closely related meaningfulness is to other organizational outcomes including perceived organizational performance, task performance, organizational citizenship behaviors, creative performance, proactivity, organizational commitment, and intentions to quit. In order to examine these questions, I developed an online survey for workers to self-report on their experiences of these concepts.

The survey was approved by the Institutional Review Board for use on human subjects. It was built and administered using Qualtrics, and the respondents were identified for the survey using Amazon's Mechanical Turk service and were paid a small amount for their response. The respondents were filtered to only include people working full time in the United States. Full time work was selected to gain insight into more dynamic and comprehensive roles, and I chose to focus on data from the United States because the literature I reviewed was primarily based in the United States and I did not want culture differences to skew the data based on the design of the survey. I integrated a unique number generator into the online survey which was given to the respondent upon completion of the survey, which they were required to enter into their Mechanical Turk response. These numbers were matched to ensure validity of the data and respondents. Two attention checks were also integrated which simply stated, "This is an attention check. Select [a designated response]." Any survey responses that did not correctly answer the attention check questions were not used in data analysis. Additionally, any responses that included a response time of below 5 minutes were not used for lack of thoughtfulness in response (my internal testing suggested this was not a reasonable time frame, even for extremely fast readers). This resulted in 27 responses being discarded from the final sample.

In total, the final sample consisted of 73 usable responses. Respondents represented a diverse range of ages, education levels, job types, and years in the role. Ages ranged from 20 years to 64 years, at an average age of 40. Education levels included high school degree (6.8\%), some college (24.7\%), two year college degree (20.5\%), four year college degree (30.1\%), professional degree (16.4\%), and doctoral degree (1.4\%). Job types ranged greatly, including a bus boy, a CPA, a pastor, a university administrator, a pilot, and an X-ray tech. Time in the respondent's current role ranged from three months to twenty-seven years, with an average of 6 years. The diversity of respondents provided a multi-faceted data pool to investigate.

The survey was structured to measure an employee's experience of each of the six categories at his or her current job, measuring the most influential sources for each category, and measuring the extent to which the respondent experienced different organizational outcomes.

The survey results provided insight into each of the following variables:

Experience of trust in the workplace. The experience of trust was measured using four items $(\alpha=.75)$ that were developed based on the "building/increasing trust in the workplace" category proposed Study 1. 
Experience of connecting individual identity and work. The experience of connecting individual identity and work was measured using three items $(\alpha=.73)$ that were developed based on the "connecting identity and work" category proposed Study 1.

Experience of connection and community among teammates. The experience of connection and community among teammates was measured using four items $(\alpha=.76)$ that were developed based on the "fostering connection and community among employees" category proposed Study 1.

Experience of growth through training and development at work. The experience of growth through training and development at work was measured using three items $(\alpha=.84)$ that were developed based on the "allowing employee growth through training and development" category proposed Study 1.

Experience of a balance between life at work and outside of work. The experience of a balance between life at work and outside of work was measured using five items $(\alpha=.82)$ that were developed based on the "enhancing/considering life outside of work" category proposed Study 1.

Experience of elements of the job characteristics model. The experience of elements of the job characteristics model was measured using eight items $(\alpha=.64)$ that were developed based on the "job design/promoting job characteristics model" category proposed Study 1.

Task performance. Task performance was measured using five items $(\alpha=.91)$ originally developed by Williams \& Anderson (1991). A sample item reads "In your current job, to what extent do you perform tasks that are expected of you?"

Organizational citizenship behavior. OCB was measured using nine items $(\alpha=.90)$ originally developed by Williams \& Anderson (1991). A sample item reads "In your current job, to what extent do you take time to listen to co-workers' problems and worries?"

Creative Performance. Creative Performance was measured using thirteen items $(\alpha=.96)$ originally developed by Scott \& Bruce (1994). A sample item reads "In your current job, to what extent do you frequently have new and innovative ideas?"

Proactivity. Proactivity was measured using thirteen items $(\alpha=.84)$ originally developed by Bateman \& Crant (1993). A sample item reads “To what extent do you agree with the following? If I see something I don't like at work, I fix it."

Job Satisfaction. Job satisfaction was measured using three items $(\alpha=.86)$ originally developed by Seashore, Lawler, Mirvis \& Cammann (1982). A sample item reads "To what extent do you agree with the following? In general, I like working at my company."

Organizational Commitment. Organizational Commitment was measured using four items $(\alpha=.90)$ originally developed by Mowday, Steers, \& Porter (1979). A sample item reads "To what extent do you agree with the following? I am willing to exert extra effort to help my organization succeed."

Intent to Quit. Intent to quit was measured using three items $(\alpha=.88)$ originally developed by Boroff \& Lewin, (1997). A sample item reads "To what extent do you agree with the following? During the next year, I will probably look for a new job outside this organization."

Meaningfulness. Meaningfulness was measured using 10 items $(\alpha=.94)$ originally developed by Steger et al. (2012). A sample item reads "How true is the following statement for you and your work? I understand how my work contributes to my life's meaning."

Perceived Organizational Performance. Perceived Organizational Performance was measured using eleven items $(\alpha=.88)$ originally developed by Delaney \& Huselid (1996). A sample item reads "Compared to other organi- 
zations that do the same kind of work, how would you compare the overall organization's performance in terms of quality of products, services, and programs?"

Personal care products and household cleaning products are particularly dangerous for those with respiratory issues. Fumes and aerosolized products can exacerbate existing conditions, like Chronic Obstructive Pulmonary Disease (COPD) and asthma. These products can also cause long-term damage to lung cells, potentially contributing to the burden of respiratory disease that is already prevalent in the U.S. If hospitals encouraged nurses, who carry out the majority of bedside education to patients, to teach patients, particularly patients and families with existing health conditions, about natural alternatives to particularly irritating products, readmission rates and exacerbations may decrease. This not only benefits the patient through improved health and fewer healthcare costs, but it also benefits hospitals, as reimbursement would increase following decreases in readmission rates.

\section{STUDY TWO RESULTS}

Study variable descriptives, including means, standard deviations and Cronbach's alphas, as well as inter-correlations are presented in Table 4. As expected, each of the practice categories identified by my taxonomy were positively and significantly correlated with employee's actual perceptions of meaningfulness at work. The category that had the lowest correlation to meaningfulness was "building/increasing trust in the workplace," ex-

\begin{tabular}{|c|c|c|c|c|c|c|c|c|c|c|c|c|c|c|c|c|c|c|c|c|c|c|}
\hline & Corre & Iation & & & & & & & & & & & & & & & & & & & & \\
\hline & Mean & $S D$ & 1 & 2 & 3 & 4 & 5 & 6 & 7 & 8 & 9 & 10 & 11 & 12 & 13 & 14 & 15 & 16 & 17 & 18 & 19 & 20 \\
\hline Female & 0.53 & 0.50 & & & & & & & & & & & & & & & & & & & & \\
\hline Age & 40.15 & 10.97 & 0.17 & & & & & & & & & & & & & & & & & & & \\
\hline Hours Per Week & 41.97 & 5.12 & -0.16 & -0.08 & & & & & & & & & & & & & & & & & & \\
\hline Years At Job & 6.33 & 5.82 & 0.07 & $.333^{* *}$ & 0.03 & & & & & & & & & & & & & & & & & \\
\hline Education Level & 4.29 & 1.24 & 0.02 & 0.07 & -0.05 & -0.04 & & & & & & & & & & & & & & & & \\
\hline Experience of Trust Practices & 3.61 & 0.84 & 0.14 & -0.05 & -0.09 & -0.23 & 0.10 & $a=0.75$ & & & & & & & & & & & & & & \\
\hline $\begin{array}{l}\text { Experience of Job Characteristics } \\
\text { Model }\end{array}$ & 3.85 & 0.70 & 0.16 & 0.05 & 0.01 & $-232^{*}$ & -0.01 & $.813^{* *}$ & $a=0.84$ & & & & & & & & & & & & & \\
\hline $\begin{array}{l}\text { Experience of Identity Connecting } \\
\text { with Work }\end{array}$ & 3.71 & 0.86 & 0.19 & 0.04 & 0.04 & -0.07 & -0.03 & $.826^{* *}$ & $.749^{* *}$ & $a=0.73$ & & & & & & & & & & & & \\
\hline $\begin{array}{l}\text { Experience of Community with } \\
\text { Co-Workers }\end{array}$ & 3.87 & 0.71 & 0.08 & 0.16 & -0.03 & -0.07 & 0.18 & $.745^{* *}$ & $.649^{* *}$ & $.714^{* *}$ & $a=0.76$ & & & & & & & & & & & \\
\hline Experience of Work/Life Balance & 3.08 & 0.99 & 0.03 & -0.06 & -0.06 & -0.08 & 0.10 & $.618^{* *}$ & $.565^{* *}$ & $.620^{* *}$ & $.602^{* *}$ & $a=0.8$ & & & & & & & & & & \\
\hline $\begin{array}{l}\text { Experience of Growth and } \\
\text { Development }\end{array}$ & 3.44 & 1.09 & 0.02 & -0.06 & -0.04 & -0.19 & -0.10 & $.703^{* *}$ & $.654^{* *}$ & $.615^{* *}$ & $.646^{* *}$ & $.755^{* *}$ & $a=0.84$ & & & & & & & & & \\
\hline Meaningfulness & 3.56 & 0.95 & 0.21 & 0.19 & 0.05 & 0.08 & 0.04 & .281 & $.441^{* *}$ & $.441^{* *}$ & $.442^{* *}$ & $.464^{* *}$ & $.450^{* *}$ & $a=0.94$ & & & & & & & & \\
\hline Task Performance & 4.44 & 0.62 & 0.16 & 0.12 & 0.13 & 0.14 & -0.08 & 0.10 & 0.12 & 0.18 & 267 & -0.12 & -0.04 & 0.08 & $a=0.91$ & & & & & & & \\
\hline $\begin{array}{l}\text { Organizational Citizenship } \\
\text { Behaviors }\end{array}$ & 3.83 & 0.74 & 0.10 & $0.252^{*}$ & $0.252^{*}$ & 0.08 & 0.11 & 0.22 & 2.78 & $.309^{* *}$ & $.459^{* *}$ & 0.18 & 0.19 & $353^{* *}$ & $.514^{* *}$ & $a=0.90$ & & & & & & \\
\hline Creative Performance & 3.58 & 0.86 & -0.12 & 0.13 & -0.03 & 0.19 & 0.14 & 0.20 & 0.15 & 0.21 & $.358^{* *}$ & $373^{* *}$ & $.374^{* *}$ & $291^{*}$ & $.281^{*}$ & $.490^{* *}$ & $a=0.96$ & & & & & \\
\hline Proactive Performance & 3.85 & 0.62 & 0.17 & 0.20 & -0.06 & 0.04 & -0.05 & $.438^{* *}$ & $.505^{* *}$ & $.558^{* *}$ & $.521^{* *}$ & $.426^{* *}$ & $.457^{* *}$ & $530^{* *}$ & $.437^{* *}$ & $.660^{* *}$ & $.634^{* *}$ & $a=0.84$ & & & & \\
\hline Job Satisfaction & 4.03 & 0.91 & $.361^{* *}$ & 0.20 & -0.18 & -0.18 & -0.08 & $.532^{* *}$ & $.622^{* *}$ & $.568^{* *}$ & $.450^{* *}$ & $329^{* *}$ & $.380^{* *}$ & $485^{* *}$ & $.290^{*}$ & $.409^{* *}$ & 0.10 & $.594^{* *}$ & $a=0.86$ & & & \\
\hline Organizational Commitment & 3.78 & 0.94 & .256 & 0.14 & -0.04 & -0.06 & -0.04 & $.518^{* *}$ & $.584^{* *}$ & $.642^{* *}$ & $.540^{* *}$ & $433^{* *}$ & $.398^{* *}$ & $583^{* *}$ & $.305^{* *}$ & $.486^{* *}$ & $.296^{*}$ & $.607^{* *}$ & $747^{* *}$ & $a=0.90$ & & \\
\hline Withdraw Intentions & 2.22 & 1.13 & -0.21 & -0.12 & -0.04 & 0.11 & 0.10 & $-.360^{*}$ & $-411^{* *}$ & $-.422^{*}$ & $-248^{* *}$ & $-261^{*}$ & $-238^{* *}$ & $.385^{*}$ & -0.13 & -0.21 & -0.11 & -437 & $.667^{* *}$ & $-6.12^{* *}$ & $a=0.88$ & \\
\hline $\begin{array}{l}\text { Organizational Performance } \\
\text { Perceptions }\end{array}$ & 2.53 & 0.57 & 0.03 & -0.02 & -0.16 & -0.13 & -0.13 & $.501^{* *}$ & $.535^{* *}$ & $.485^{* *}$ & $.420^{* *}$ & $443^{* *}$ & $.459^{* *}$ & $418^{* *}$ & 0.08 & .257 & $.362^{* *}$ & $.565^{* *}$ & $.565^{* *}$ & $.621^{* *}$ & $-.436^{* *}$ & $y=0.88$ \\
\hline
\end{tabular}

Note: Diagonal entries are scalable reliabilities. $\mathrm{N}=73 .{ }^{*}$ Correlation is significant at the 0.05 level (2-tailed). ${ }^{* *}$ Correlation is significant at the 0.01 level (2-tailed). 
plaining almost $8 \%$ of the variance in meaningfulness. The category that had the highest correlation to meaningfulness was "enhancing/considering life outside of work" with a correlation of .464. Excluding the lowest correlation, the rest of the categories all correlated with meaningfulness to a fairly similar degree, all falling within .023 of each other (the average correlation size for the various practice types on meaningfulness was .42). In sum, the practices identified in my taxonomy explain anywhere from $7.9-21.5 \%$ of the variance in perceived meaningfulness in the current sample.

The organizational outcomes measured were all found to be significantly correlated with meaningfulness and in the expected direction ( $\mathrm{p}<.05)$, except task performance, which demonstrated a correlational value that was not statistically different than zero. All were found to be positively correlated with meaningfulness, except intentions to quit, which is the outcome that follows the reviewed literature. Aside from this outlier, the other organizational outcome that had the lowest correlation to meaningfulness was creative performance at 29 . The organizational outcome that was most closely related to meaningfulness was organizational commitment, with a correlation of .58. These results reflect consistency with previous research, with the exception of task performance.

$\begin{array}{lll}\text { Trust } & \text { Mean } & \text { SD } \\ \text { Self } & 4.15 & 0.84 \\ \text { Supervisor } & 3.51 & 1.02 \\ \text { Organization } & 2.99 & 0.96 \\ \text { Coworkers } & 3.58 & 1.00 \\ \text { Others } & 2.78 & 1.12 \\ \text { Society } & 2.38 & 1.08 \\ & & \\ & & \\ \text { Non-Work } & \text { Mean } & \text { SD } \\ \text { Self } & 4.14 & 0.93 \\ \text { Supervisor } & 2.82 & 1.23 \\ \text { Organization } & 2.38 & 1.09 \\ \text { Coworkers } & 2.66 & 1.07 \\ \text { Others } & 23.03 & 1.12 \\ \text { Society } & 2.05 & 1.10\end{array}$

$\begin{array}{ll}\text { Growth } & \text { Mean } \\ \text { Self } & 3.89 \\ \text { Supervisor } & 3.52 \\ \text { Organization } & 3.18 \\ \text { Coworkers } & 2.97 \\ \text { Others } & 2.15 \\ \text { Society } & 1.95 \\ & \\ & \\ \text { Community } & \text { Mean } \\ \text { Self } & 3.66 \\ \text { Supervisor } & 2.96 \\ \text { Organization } & 2.82 \\ \text { Coworkers } & 3.41 \\ \text { Others } & 2.38 \\ \text { Society } & 2.12\end{array}$

$S D$
1.01
1.26
1.23
1.07
1.20
1.23

$S D$
1.04
1.15
1.10
1.04
1.05
1.08

$\begin{array}{lll}\text { Identity } & \text { Mean } & \text { SD } \\ \text { Self } & 4.01 & 0.89 \\ \text { Supervisor } & 2.96 & 1.18 \\ \text { Organization } & 2.64 & 1.18 \\ \text { Coworkers } & 3.16 & 1.22 \\ \text { Others } & 2.60 & 1.13 \\ \text { Society } & 2.33 & 1.08 \\ & & \\ & & \\ \text { Job Design } & \text { Mean } & \text { SD } \\ \text { Self } & 3.68 & 1.05 \\ \text { Supervisor } & 3.68 & 1.10 \\ \text { Organization } & 3.38 & 1.05 \\ \text { Coworkers } & 3.07 & 1.05 \\ \text { Others } & 2.03 & 1.14 \\ \text { Society } & 1.79 & 1.01\end{array}$

\section{Table 5}

The evaluations of the sources that are most influential in creating an employee's experience of each of the six categories yielded insightful results that can be seen in table 5. I evaluated the mean of each of the six sources for each category, quantifying the results of the responses ranging from "a very small extent" to "a very large extent" between 1 and 5. The source with the highest mean for all categories was "self," with the exception of "job design/promoting job characteristics model" which had equal results for the highest mean in the source of "self" and "supervisor/manager." Not including "self" the source that received the highest mean in each category was: "coworkers" for "building/increasing trust in the workplace," "coworkers" for "connecting identity and work," "coworkers" for "fostering connection and community among employees," "supervisor/manager" for "allowing employee growth through training and development," "others" for "enhancing/considering life outside of work," and "supervisor/manager" for "job design/promoting job characteristics model."

\section{STUDY TWO DISCUSSION}

The results of this study provide insight to the answers to Research Questions 2 and 3. As expected each of the practice types significantly and positively influenced perceptions of meaningfulness, and, moreover, meaningfulness explained significant variance in several important outcomes. Of note, however, meaningfulness did not explain significant variance in task performance, suggesting that meaningfulness may provide less obvious but nevertheless valuable gain in employee outcomes for organizations. 
In response to research question 3a, this study provided data that emphasized the central role that an individual plays in his or her own experience of meaningfulness, regardless of which category or strategy is being used to promote meaningfulness. It also revealed the importance of coworkers and supervisors in the creation of meaningfulness, emphasizing the benefits organizations can reap from hiring individuals who possess the abilities to promote meaningfulness or developing and training existing employees to be able to exert these skills and practices to increase meaningfulness on an organization-wide basis. My results also provide some insight into the sources that drive each avenue for meaningfulness. Interestingly, results suggest the "the self" plays an incredibly important role in determining meaningfulness, though supervisors and coworkers likewise play influential roles for some practice types.

\section{GENERAL DISCUSSION}

\section{Summary}

Both the literature review and the study presented provide an organized and comprehensive look at the topic of meaningful work. Previously, the literature on this topic existed in separate realms with distinct facets, without being integrated into a single location combining elements of sources of meaningfulness, individual and organizational outcomes of meaningfulness, practices that can be implemented across various sources to promote meaningfulness, and many other concepts covered in this study. By integrating this information, I have advanced a more integrated review of the topic, and through the creation of the taxonomy, have developed opportunities for more strategic practical and scholarly opportunities for further investigation. The second study I conducted provides much needed insight into the most influential strategies for promoting meaningfulness in an organization and the sources that are most influential in doing so.

\section{Theoretical Implications}

This study has effectively combined a body of literature that existed in many facets, separating the concepts of why meaningfulness in work is important and how to create it, and combined these concepts into a cohesive evaluation of the concept of meaningful work. By bringing this work together, new insight can be gained into concepts such as how certain antecedents are specifically linked to results of meaningfulness, what individuals, supervisors, and organizations as a whole can specifically do to increase meaningfulness, and how certain practices are specifically derived from conditions necessary to experience work as meaningful. The conjunction of this literature opens opportunities for further research regarding how aspects of meaningfulness such as these are linked to one another.

In conducting a review of existing literature, I found resounding agreement among many sources of the positive outcomes of an increased sense of meaningfulness. The convergence among scholars as to the positive effects of meaningfulness demonstrates the importance of furthering the study of this concept theoretically, in order to provide organizations continued, refined guidance on how to effectively create a culture of meaningfulness among their employees. The research I have conducted contributes to the advancement of the study of this concept, opening doors for further development of understanding of why meaningfulness matters and how it can be promoted.

Additionally, the advancement of a taxonomy for categorizing the types of practices that promote meaningfulness in an organization provides an organized method for understanding how increased experiences of meaningfulness among employees can be achieved. These categories provide specific guidance to organizations of strategies for promoting meaningfulness and shed light on the necessary factors for completely providing a full sense of meaningfulness to employees of many personality types. This taxonomy provides many opportunities for further research in understanding how organizations can promote meaningfulness and which methods are most effective.

The areas I examined in Study 2 provide excellent examples of the type of studies that can be conducted using the context of the taxonomy I created in Study 1. The results of my survey illustrate the areas that are most influential in fostering or promoting an increased sense of meaningfulness for employees. 


\section{Practical/Managerial and Individual Implications}

The content of this study confirms many of the existing anecdotes and research that assert the importance of fostering a sense of meaningfulness in work. A review of previous research asserts that the results of an increased sense of meaningfulness among a workforce provides intangible benefits such as increased happiness and understanding of self-concept for employees, but also provide opportunities for organizations to see manifestations of these changes in a quantitative way. Further, the literature agrees that as workers' sense of meaningfulness increases, they are able to work more effectively in teams, they work longer hours even if not getting paid more, they have fewer days absent from work, and many other outcomes that allow an organization to improve its bottom line by investing in practices that promote meaningfulness for their employees. The content of my research provides further support of these trends.

The integration of a largely fragmented set of literature I have developed provides a comprehensive look at why this is important for organizations to pursue, but also how this can be achieved specifically. By linking these two interconnected concepts together into one cohesive source, organizations are supplied with a compelling look at how to achieve an increased sense of meaningfulness for their workforces. Additionally, the creation of the taxonomy for organizing the many practices that can promote meaningfulness provides specific guidance for organizations to strategically pursue different avenues for addressing the various ways their employees can experience meaningfulness.

The results of Study 2 provide specific insight into the strategies organizations can pursue to promote meaningfulness and what role each potential source plays in the promotion of meaningfulness within each of those strategies. The implications of these insights provide guidance for organizations as well as individuals. The strongest message communicated by the data is that individuals play the most influential role in creating and increasing their experience of meaningfulness. In evaluating all six categories in the taxonomy to determine what the most influential sources were, consistently, and often by a significant margin, the self was determined to be the most important influence on experiencing meaningfulness. This emphasizes the role an individual plays in his or her experience of meaningfulness and how important linking work roles and identity is. Individuals must take responsibility for the perspective they take in their life and work, and ensure they are intentionally aligning their goals and tasks if they desire a sense of meaningfulness in their work. Likewise, organizations should examine and find ways to select employees who are willing and able to construct meaningful experiences.

Although individuals play an incredibly important role in their own experience of meaningfulness, the focus of this research is on what organizations can do to promote meaningfulness among their employees. Organizations should not only feel compelled to provide this for employees on a moral ground, but also should be seeking ways to promote meaningfulness for the financial and other benefits it can offer them. The results of Study 2 provide insight into some of these benefits through the examination of the relationships between meaningfulness and various organizational outcomes. Meaningfulness was found to be positively correlated with organizational performance, organizational citizenship behaviors, creative performance, proactive performance, job satisfaction and organizational commitment, and negatively correlated with intentions to quit. These correlations were all statistically significant and all clearly represent outcomes all organizations desire overall or for their employees. Each of these also represents the opportunity to earn more profits or prevent costs as employees perform more effectively and creatively and show commitment to the company rather than withdrawing or quitting, saving turnover costs. Organizations should be compelled to promote meaningfulness based on the organizational outcomes that are likely to come along with this promotion.

With that in mind, it is important to evaluate what organizations can do to most effectively promote meaningfulness. Interestingly, the category that had the highest correlation to meaningfulness was "enhancing/ considering life outside of work." Because this was the highest correlation, this is the category that is most closely linked to meaningfulness based on things that organizations can directly do to improve meaningfulness. Based on this insight, organizations that are seeking to improve meaningfulness among their employees should strive to create a balance for their employees between life at work and life outside of work using the practices listed in Study 1 or other strategies that will improve this for their employees. For example, offering employees the 
opportunity to take part in a sabbatical later in their careers has been found to rejuvenate their enthusiasm and passion for the work they are doing, even though it requires the organization to manage operations without the employee for a period of time (Cartwright \& Holmes, 2006).

Allowing employee growth through training and development also was very highly correlated with meaningfulness. This similarly emphasizes the benefits that organizations can reap by investing in training and development programs for their employees or creating cross-functional teams that allow employees to grow their skills. These practices can lead to increased senses of meaningfulness among employees, which ultimately provides positive net outcome for the organization as employees become more productive and committed to their work.

\section{Future Research Opportunities and Limitations}

The creation of a taxonomy for the practices that promote meaningfulness in an organization provides many opportunities for future research based on these categories. Though Study 2 provided an example as to the types of questions that can be answered using this taxonomy, many more research opportunities exist. For example, these categories could be studied to discover trends connected to their importance or influence depending on life stage, field of work, personality type, size of organization, or other similar factors. Similarly, I did not explore the unique interactions and combinations between various practices, which might yield even more utility.

The integration of the disjointed literature also provides opportunities to study other links across the process of creating meaningfulness and the outcomes of an increased sense of meaningfulness. By combining a fuller range of aspects surrounding the topic, this study demonstrates inputs and outcomes that can be further evaluated to understand how these specific inputs and outputs are connected and how closely they affect each other.

The data in the content validation study is limited by the pool of subject matter experts and the method for establishing a designated category for each practice. The data would have been strengthened by the input of other subject matter experts, expanding the sample size. Additionally, the category I specified as the chosen category for each practice was simply chosen using the highest mean score for each category. The process of identifying subject matter experts' consensus on a category for a given practice could have been strengthened by taking a more complex approach (e.g., factor analysis) that accounted for outlying data or other notable trends in the data. Additionally, the process I used did not include protocol for practices that received high scores in multiple categories, or a slightly weak score in the highest category. Further evaluation of this data with these considerations may give new insight to the results of the study.

This study is limited by a focus on literature primarily from the United States, and further research many include investigation as to which principles universally translate across many cultures, and which principles vary. Additionally, the specific relationships between meaningfulness and organizational outcomes have not been collectively studied in a quantitative way to evaluate the strength of the relationships between meaningfulness and each outcome to determine which are most heavily influenced by an increased sense of meaningfulness.

The data collection for Study 2 was limited by its design as a self-response, single source survey, and could have been more effective if it had included evaluations from a manager or other coworkers. Additionally, the survey was a one-time response survey, and results could have been enhanced by evaluating respondents over time. These features raise substantive concerns relating to common method bias that should be overcome in future work. This data also relies on evaluation of correlation, which doesn't provide insight into causality or an understanding of the true role that meaningfulness or increasing meaningfulness plays in each of the outcomes and inputs that were evaluated.

\section{CONCLUSION}

This study provides an in-depth, comprehensive review of the existing, scattered literature regarding the conditions necessary for experiencing work as meaningful, the sources meaningfulness can be derived from, and the valuable outcomes of meaningfulness that serve as a confirmation of the desirability of meaningful work. By bringing this data together, I was able to closely evaluate the role an organization can play in promoting mean- 
ingfulness in work and compiled an extensive list of specific practices an organization can implement to promote meaningfulness. Using this list of practices and frameworks from the literature I reviewed, I was able to develop a taxonomy of six general categories these practices fell into, which was quantitatively validated by ten subject matter experts.

Using this taxonomy, I explored the relationship between each of the six categories and their connection to meaningfulness, as well as the most influential sources in promoting each of these six categories. I also evaluated the relationship between meaningfulness and other organizational outcomes, most of which were found to have a strong correlation to meaningfulness. The results of this study point to the extremely significant role individuals play in their experience of meaningfulness, largely through their understanding of how their personal identity and values are connected to those of the organization they are working for and how they are connected to the physical work they are performing. Additionally, the link to organizational outcomes makes a compelling case for organizations to pursue promoting meaningfulness, with some of the most effective strategies predicted to be offering opportunities to create a balance between life at work and life outside of work and providing training and opportunities for employees to grow and develop. As future generations continue to demand meaningful work and organizations continue to recognize its value, we can anticipate seeing continued growth in the awareness and promotion of meaningfulness in work. 


\section{REFERENCES}

Amortegui, Jessica. (2014, June 26). "Why Finding Meaning at Work is More Important than Feeling Happy." Fast Company. Retrieved November 1, 2016, from https://www.fastcompany.com/3032126/how-to-findmeaning-during-your-pursuit-of-happiness-at-work

Arnold, Kara. A., et al. "Transformational Leadership and Psychological Well-Being: The Mediating Role of Meaningful Work." Journal of Occupational Health Psychology. 12.3 (2007):193-203. http://dx.dsi. org/10.1037/1076-8998.12.3.193

Ashforth, Blake. E., and Fred Mael. "Social Identity Theory and the Organization." Academy of Management Review. 14.1 (1989): 20-39. http://dx.dsi.org/10.5465/AMR.1989.4278999

Bains, Gurnek. Meaning, Inc.: The Blueprint for Business Success in the 21st Century. London: Profile Books. 2007.

Bateman, Thomas. S. and J. Michael Crant. "The Proactive Component of Organizational Behavior: A Measure and Correlates." Journal of Organizational Behavior. 14.2 (1993): 103-18. http://www.jstor.org/sta ble/2488028

Boroff, Karen. E. And David Lewin. "Loyalty, Voice, and Intent to Exita Union Firm: A Conceptual and Empiricle Analysis.” ILR Review. 51.1 (1997): 50-63. http://dx.doi.org/10.2307/2525034.

Boverie, Patricia E. and Michael Kroth. Transforming Work: The Five Keys to Achieving Trust, Commitment, and Passion in the Workplace. Cambridge: Perseus Books. 2001.

Bowie, Norman. E. "A Kantian Theory of Meaningful Work." Journal of Business Ethics. 17.9 (1998): 1083-92. http://www.jstor.org/stable/25073937

Carpenter, Nichelle C. et al. (2016). “Don’t Forget the Items: Item-Level Meta-Analytic and Substantive Validity Techniques for Reexamining Scale Validation." Organizational Research Methods. 19.4 (2016): 616-50. http://dx.doi.org10.1177/1094428116639132

Cartwright, Susan and Nicola Holmes. "The Meaning of Work: The Challenge of Regaining Employee Engagement and Reducing Cynicism." Human Resource Management Review. 16.2 (2006):199-208. https://doi. org/10.1016/j.hrmr.2006.03.012

Caudron, Shari. “The Search for Meaning at Work." Training \& Development. 51.9 (1997): 24-28.

Chalofsky, Neal E. Meaningful Workplaces: Reframing How and Where We Work. San Francisco: Wiley \& Sons. 2010.

Cohen-Meitar, Ravit, Abraham Carmeli, and David A.Waldman. "Linking Meaningfulness in the Workplace to Employee Creativity: The Intervening Role of Organizational Identification and Positive Psychological Experiences." Creativity Research Journal. 21.4 (2009): 361-75.

Cooley, Charles Horton. Human Nature and the Social Order. New York: Scribner's. 1902. https://hdl.handle. net/2027/nyp.33433061787077

Cross, Rob, Wayne Baker, and Andrew Parker. "What Creates Energy in Organizations?." MIT Sloan Management Review. 44.4 (2003): 51-57. http://sloanreview.mit.edu/article/what-creates-energy-in-organizations/

Delaney, John T. And Mark A. Huselid. "The Impact of Human Resource Management Practices on Perceptions of Organizational Performance." Academy of Management Journal. 39.4 (1996): 949-69. http://www.jstor. org/stable/256718 
Dik, Bryan J., et al. "Purpose and Meaning in Career Development Applications." The Counseling Psychologist. 34.4 (2014): 558-85. https://doi.org/10.1177/0011000014546872

Dik, Bryan. J., Adam M. Sargent, and Michael F. Steger. "Career Development Strivings: Assessing Goals and Motivation in Career Decision-Making and Planning.” Journal of Career Development. 35.1 (2008): 23-41. http://dx.doi.org/10.1177/0894845308317934

Frankl, Victor E. Man's Search for Meaning: An Introduction to Logotherapy. 1959. New York: Simon \& Schuster. 1984.

Gioia, Dennis A., and Kumar Chittipeddi. "Sensemaking and Sensegiving in Strategic Change Initiation." Strategic Management Journal. 12.6 (1991): 433-48. http://dx.doi.org10.1002/smj.4250120604

Gray, Barbra, Michael G. Bougon, and Anne Donnellon. "Organizations as Constructions and Destructions of Meaning." Journal of Management. 11 (1984): 83-98. http://dx.doi.org10.1177/014920638501100212.

Hackman, J. Richard and Greg R. Oldham. "Motivation Through the Design of Work: Test of a Theory. Organizational Behavior and Human Performance. 16.2 (1976): 250-79. https://doi.org/10.1016/00305073(76)90016-7

Oldham, G. R., \& Hackman, J. R. "Work Design in the Organizational Context. "Research in Organizational Behavior. Vol 2 Greenwich: CT. JAI Press. 1980.

Hackman, Richard J., \& Oldham, G. R. Work Redesign. Reading: MA. 1980.

Harpaz, Itzhak and Xuanning Fu. "The Structure of the Meaning of Work: A Relative Stability Amidst Change." Human Relations.55.6 (2002): 639-67. https://doi.org/10.1177/0018726702556002

Herman, Roger E. And Joyce L. Gioia. (1998). “Making Work Meaningful: Secrets of the Future-Focused Corporation." The Futurist. 32.9 (1998): 24.

Kahn, William. A. "Psychological Conditions of Personal Engagement and Disengagement at Work." Academy of Management Journal. 33.4 (1990): 692-724. https://doi.org/10.2307/256287

Kamdron, Tiiu. (2005). "Work Motivation and Job Satisfaction of Estonian Higher Officials." International Journal of Public Administration. 28.13/14 (2005): 1211-40. http://dx.doi.org/10.1080/01900690500241085

Keane, Jim. “Meaningful Work Should Be Every CEO’s Top Priority." Harvard Business Review Digital Articles. (2015): 2-4. https://hbr.org/2015/11/meaningful-work-should-be-every-ceos-top-priority

Martela, Frank. "Meaningful work-an integrative model based on the human need for meaningfulness." Academy of Management Annual Meeting in Montréal Conference. Quebec.

Michaelson, Christopher, et al. "Meaningful Work: Connecting Business Ethics and Organization Studies.” Journal of Business Ethics. 121.1 (2014): 77-90. https://doi.org/10.1007/s10551-013-1675-5

Monnot, Matthew J. And Terry A. Beehr. "Subjective Well-Being at Work: Disentangling Source Effects of Stress and Support on Enthusiasm, Contentment, and Meaningfulness." Journal of Vocational Behavior. 85.2 (2014): 204-18. https://doi.org/10.1016/j.jvb.2014.07.005

Mowday, Richard. T., et al. "The Measurement of Organizational Commitment." Journal of Vocational Behavior. 14.2 (1979): 224-47. https://doi.org/10.1016/0001-8791(79)90072-1 
Brief, Arthur P. et al. "Studying Meanings of Work: The Case of Work Values." Meanings of Occupational Work: A Collection of Essays. Arthur P. Brief and Walter R. Nord, Eds. Lexington: Lexington Books, 1991. 21-64. Print.

Pratt, Michael. G. And Blake E. Ashforth. “Fostering Meaningfulness in Working and at Work." Positive Organizational Scholarship: Foundations of a New Discipline. San Francisco: Berrett-Koehler, 2003. 30927. Print.

Pratt, Michael et al. "Doing Well, Doing Good, and Doing With: Organizational Practices for Effectively Cultivating Meaningful Work.” Purpose and Meaning in the Workplace. Washington, D.C., 2013. 173-96. Print.

Pryce-Jones, Jessica. Happiness at Work: Maximizing your Psychological Capital for Success. Oxford: Wiley, 2010. Print.

Rosso, Brent. D., Dekas, Kathryn H., and Amy Wrzesniewski. “On the Meaning of Work: A Theoretical Inte gration and Review." Research in Organizational Behavior. 30. (2010): 91-127. https://doi.org/10.1016/j. riob.2010.09.001

Scott, Susan G., and Reginald A. Bruce. "Determinants of Innovative Behavior: A Path Model of Individual Innovation in the Workplace." Academy of Management Journal. 37.3 (1994): 580-607. https://doi.org/10.2307/256701

Scroggins, Wesley A. "Antecedents and Outcomes of Experienced Meaningful Work: A Person-Job Fit Perspective." Journal of Business Inquiry. 7.1 (2008): 68-78.

Cammann, Cortlandt, Edward Lawler, and Stanley Seashore. "The Michigan Organizational Assessment Questionnaire." Assessing Organizational Change: A Guide to Methods, Measures, and Practices. New York: Wiley, 1983. 71-198. Print.

Shamir, Boas. "Meaning, Self and Motivation in Organizations." Organization studies, 12.3 (1991): 405-24. https:// doi.org/10.1177/017084069101200304

Shuck, Brad et al. "Employee Engagement: An Examination of Antecedent and Outcome Variables." Human Resource Development International. 14.4 (2010): 427-45. http://dx.doi.org/10.1080 /13678868.2011.601587

Sparks, John. R., and Joseph A. Schenk. "Explaining the Effects of Transformational Leadership: An Investigation of the Effects of Higher-Order Motives in Multilevel Marketing Organizations." Journal of Organizational Behavior. 22.8 (2001): 849-69. http://www.jstor.org/stable/3649575

Steger, Michael. F. et al. "Measuring Meaningful Work: The Work and Meaning Inventory (WAMI)." Journal of Career Assessment. 20.3 (2012): 322-37. https://doi.org/10.1177/1069072711436160

Stryker, Sheldon, and Peter J. Burke. "The Past, Present, and Future of an Identity Theory." Social Psychology Quarterly. 63.4 (2000): 284-97. http://www.jstor.org/stable/2695840

Stryker, Sheldon and Richard Serpe "Commitment, Identity Salience, and Role Behavior: Theory and Research Example." Personality, Roles, and Social Behavior. New York: Springer. 1982. 199-218. https://doi.org/10.1007/978-1-4613-9469-3_7

Treadgold, Richard. "Transcendent Vocations: Their Relationship to Stress, Depression, and Clarity of Self Concept." Journal of Humanistic Psychology. 39.1 (1999): 81-105. https://doi. org/10.1177/0022167899391010 
Van Der Vegt, Gerben, et al. “Team Members' Affective Responses to Patterns of Intragroup Interdependence and Job Complexity." Journal of Management. 26.4 (2000): 633-55. https://doi.org/10.1016/S01492063(00)00050-7

Weick, Karl. E. (1995). Sensemaking in Organizations. Vol. 3. New York: Sage, 1995. Print.

Williams, Larry J. and Stella E. Anderson. "Job Satisfaction and Organizational Commitment as Predictors of Organizational Citizenship and In-Role Behaviors." Journal of Management. 17.3 (1991): 601-17. https:// doi.org/10.1177/014920639101700305

Wrzesniewski, Amy, et al. "Interpersonal Sensemaking and the Meaning of Work." Research in Organizational Behavior. 25. (2003): 93-135. https://doi.org/10.1016/S0191-3085(03)25003-6

Wrzesniewski, Amy, et al. "Jobs, Careers, and Callings: People's Relations to Their Work." Journal of Research in Personality. 31.1 (1997): 21-33. https://doi.org/10.1006/jrpe.1997.2162

Yeoman, Ruth. "Conceptualising Meaningful Work as a Fundamental Human Need." Journal of Business Ethics. 125.2 (2014): 235-51. https://doi.org/10.1007/s10551-013-1894-9 